\title{
CARACTERÍSTICA DA GERMINAÇÃO E MORFOLOGIA DO ENDOCARPO E PLÂNTULA DE TAPEREBÁ (Spondias mombin L.) - ANACARDIACEAE ${ }^{1}$
}

\author{
DANIEL DE MENEZES AZEVEDO², ANGELA MARIA DA SILVA MENDES 3 , \\ ANTENOR FRANCISCO DE FIGUEIREDO ${ }^{4}$
}

\begin{abstract}
RESUMO - O taperebá (Spondias mombin L.) é uma espécie frutífera bastante apreciada no Norte e Nordeste do País. Porém, alguns problemas fitotécnicos ainda persistem, dentre os quais a germinação irregular e distribuída ao longo do tempo. O objetivo deste trabalho foi estudar as características de germinação das sementes, indicando algumas causas que contribuem para a baixa germinação das sementes, além de contribuir com a produção de mudas de boa qualidade. O trabalho foi desenvolvido sob condições ambientais no Instituto de Ciências Biológicas da Universidade Federal do Amazonas. Os endocarpos foram colocados para secar ao ambiente e, após 24 horas, foram determinadas as massas de 20 endocarpos e, posteriormente, colocados para germinar; a cada cinco dias, este procedimento foi repetido por um período de 135 dias. As sementes de taperebá não perdem a viabilidade quando colocadas para secar ao ambiente por 135 dias. O período de dessecamento das sementes diminuiu o tempo médio de germinação. Os endocarpos de taperebá são euricárpicos, cada endocarpo contém 1 a 4 sementes viáveis. A germinação do taperebá é do tipo epígeo fanerocotiledonar. A protrusão da raiz primária e do hipocótilo ocorre na parte truncada do endocarpo. De cada endocarpo, pode germinar mais de uma semente ao mesmo tempo, porém apenas uma raiz principal se desenvolve.
\end{abstract}

Termos para indexação: Spondias mombin L., tempo médio de germinação, morfologia,

\section{GERMINATION CHARACTERISTIC AND MORPHOLOGY OF THE ENDOCARP AND SEEDLING OF TAPEREBÁ (Spondias mombin L.) - ANACARDIACEAE}

\begin{abstract}
Taperebá (Spondias mombin L.) is a fruit species very appreciated in northern and northeastern Brazil. However, a few phytotechnical problems still persist, such as irregular and distributed germination along the time. The aim of the present paper was to study seed germination characteristics by pointing out some causes, which contribute for poor seed germination, as well as providing useful information for producing high quality seeds. The present study was carried out under environmental conditions at the Biological Science Institute in the Federal University of Amazonas. The endocarps were put to dry in the open air. After $24 \mathrm{~h}$ the masses of 20 endocarps were determined and then put to germinate; this procedure was repeated every five days for 135 days. Taperebá seeds lost no viability when put to dry in the air for 135 days. The seeds drying period diminished its average germination time. Taperebá endocarps are eurocarpic, each one containing from 1 to 4 viable seeds. Taperebá germination is the epigeous fanerocotiledonar type. Radicle and hypocotyls protrusion takes place on the truncated portion of the endocarp. More than one seed can germinate at the same time from the endocarp, yet only one main root will develop.
\end{abstract}

Indexing terms: Spondias mombin L., average germinating time, morphology,

O taperebá, frutífera da família Anacardiaceae e originária da América tropical, encontra-se distribuído em todas as regiões do Brasil, sendo conhecido, também, por vários outros nomes populares, como cajazeiro, cajazeira, cajá, cajá-mirim, cajazeiro-miúdo, acajá, acajaíba, imbuzeiro e cajá azedo (Braga, 1976; Cavalcante, 1976).

Apesar de bastante apreciado no Norte e Nordeste do País, alguns problemas fitotécnicos relacionados à produção da espécie ainda persistem, dentre os quais a germinação irregular e distribuída ao longo do tempo, constituindo-se, conseqüentemente, no principal deles para a produção de mudas a partir de sementes. Carvalho et al. (2000) referemse ao baixo poder germinativo das sementes de taperebá como fator dificultador de sua utilização no processo de propagação sexuada. Souza et al. (2000) citam que o endocarpo do taperebá é do tipo Spondias, o qual é composto de um conjunto de células fortemente lignificado e irregularmente orientado em esclerênquima.

O estudo morfológico de sementes e plântulas constitui-se num trabalho preparatório da análise do ciclo vegetativo das espécies (Melo, 2001). A morfologia das sementes, aliada às observações das plântulas, permite fazer a identificação das estruturas, oferecendo subsídios à interpretação correta dos testes de germinação (Araújo \& Mattos, 1991).

Para suprir a necessidade de informações sobre a espécie, considerando o amplo potencial econômico do cultivo e de sua exploração agroindustrial, o objetivo deste trabalho foi estudar as características de germinação das sementes de taperebá, com indicações de algumas causas que contribuem para a baixa germinação, e caracterizar a morfologia da unidade de dispersão, germinação e plântula, de modo a contribuir com a produção de mudas de boa qualidade.

Este trabalho foi desenvolvido sob condições ambientais, em casa de vegetação da Faculdade de Ciências Agrárias da Universidade Federal do Amazonas em Manaus - AM, no período de janeiro de 2001 a junho de 2001.

Os frutos, completamente maduros, foram coletados de três matrizes no Câmpus da Universidade. Após a coleta de 2.000 frutos, estes foram manualmente despolpados e lavados em água corrente até a eliminação completa dos resíduos da polpa. Após a secagem em bandejas plásticas, sobre papel toalha por 24 horas em ambiente de laboratório, os endocarpos foram tratados com Benomyl via seca ( $100 \mathrm{~g} / \mathrm{kg}$ de semente). Posteriormente, foi realizada a determinação da massa média de 20 endocarpos e colocados para germinar em caixas de isopor contendo, como substrato, areia lavada com irrigação diária. Este procedimento foi repetido a cada cinco dias por um período de 135 dias. A germinação foi acompanhada diariamente, considerando-se germinados os endocarpos que produziram plântulas com as características normais apresentadas no estudo da morfologia. Quando emergiu mais de uma plântula normal por endocarpo, somente uma foi contada para fins de cálculo.

Avaliaram-se as seguintes características: percentagem de germinação, início, término e tempo médio da germinação em dias (Silva \& Nakagawa, 1995), após o dessecamento dos endocarpos.

O delineamento experimental foi inteiramente casualizado em 28 tratamentos (dias de secagem), divididos em quatro repetições de cinco sementes. Também foi ajustada equação de regressão para relacionar a massa dos endocarpos com o tempo de secagem.

$\mathrm{Na}$ descrição morfológica do processo germinativo, foram consideradas, apenas, as unidades que apresentaram raiz primária, hipocótilo e cotilédones normais. As amostras das diversas fases da germinação e de plântula foram fixadas em FAA (Formol-Ácido acético-

\footnotetext{
1 (Trabalho 020/2004). Recebido: 11/04/2004. Aceito para publicação: 03/12/2004.

${ }^{2}$ Eng. Agrônomo - MSc. - Universidade Federal do Amazonas, azevedodm@ hotmail.com.

${ }^{3}$ Eng. Agrônoma, MSc. - Universidade Federal do Amazonas, amendes@ufam.edu.br.

${ }^{4}$ Eng. Agrônomo, Dr. Titular - Universidade Federal do Amazonas, antenor@ufam.edu.br.
} 


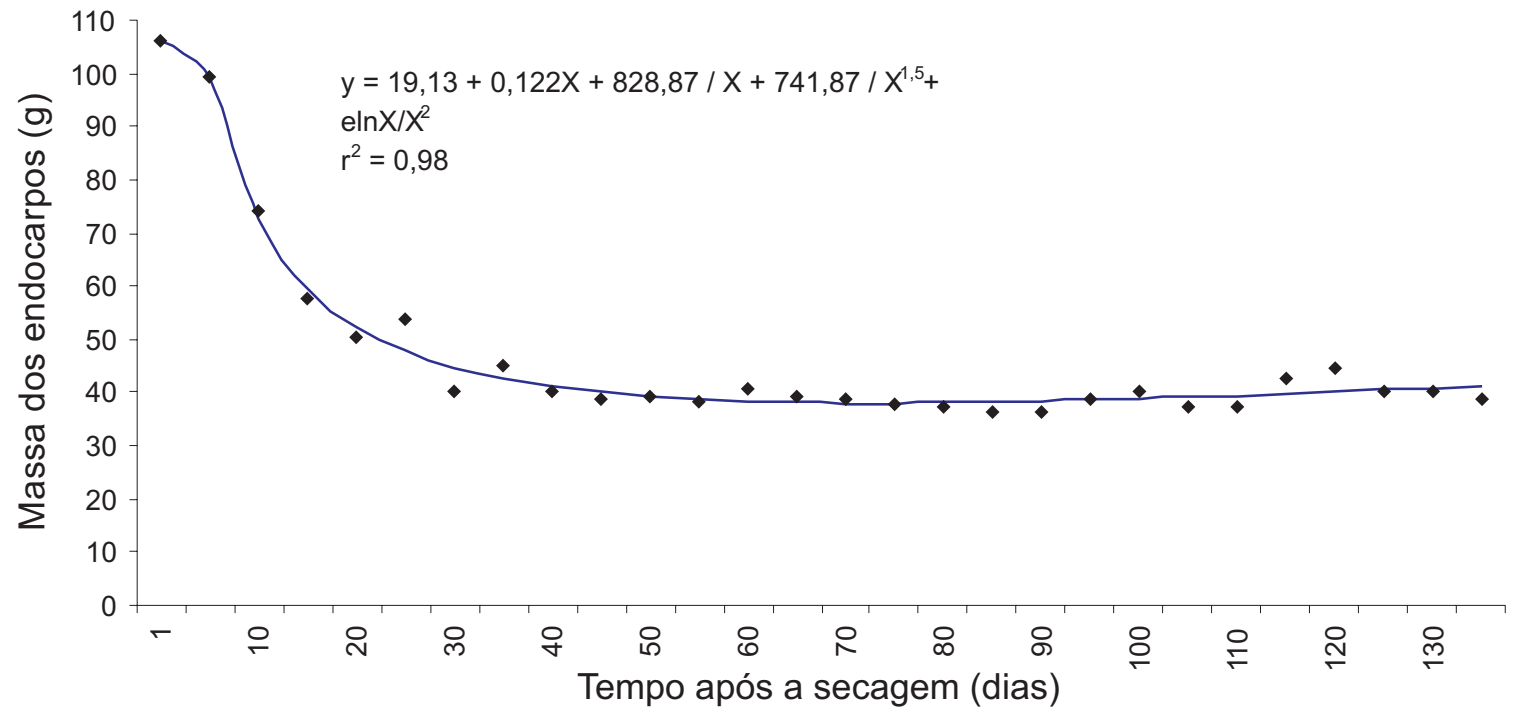

FIGURA 1 - Massa média de 20 endocarpos de taperebá (Spondias mombin L.) após o dessecamento.

Álcool) a 50\% (Johansen, 1940) para avaliações e ilustrações.

Para a caracterização morfológica das unidades de dispersão, foram determinadas as medidas de comprimento e diâmetro, em milímetros, de 100 endocarpos, divididos em quatro repetições, com auxílio de paquímetro digital. Também determinou-se o número de lóculos e sementes por endocarpo. Para cada variável estudada, calcularam-se a média, o desvio-padrão e os valores máximo e mínimo.

As características avaliadas foram a forma, a cor e a consistência dos endocarpos das sementes, da raiz primária, do hipocótilo, do epicótilo e dos protófilos. A terminologia empregada e as características observadas nas descrições estão de acordo com trabalhos de Font-Quer (1963), Duke (1965), Amorim (1996) e Melo (2001).

Na Figura 1, é apresentado o comportamento da massa de 20 endocarpos durante 135 dias de secagem ao ambiente. No início, com um dia de secagem, a massa foi bastante alta (106,3 g), porém, após cinco dias, o endocarpo tende a perder água rapidamente, de 99,3 $\mathrm{g}$ para 38,6 g, aos 45 dias. Após este período, a massa tendeu a estabilizarse e aos 115 dias não houve mais perda; a partir daí, observa-se um pequeno ganho de massa.

Os endocarpos perderam massa rapidamente no período de um até 45 dias aproximadamente, o que deve corresponder à perda de umidade e, a partir desta data até o final do experimento, os endocarpos alcançaram o equilíbrio higroscópico. Isso fez com que as massas continuassem estáveis, o que pode ser confirmado pela Figura 1 e Tabela 1.

A percentagem de germinação do taperebá foi em torno de $50 \%$ aos 130 dias de dessecamento (Tabela 1); porém, quando as sementes foram expostas a secagem ao ambiente, por 135 dias, elevouse para $70 \%$. Os reduzidos valores de germinação, até aos 130 dias de

TABELA 1 - Massa do endocarpo e características da germinação de sementes de taperebá (Spondias mombin L.) em relação ao tempo de secagem ao ambiente.

\begin{tabular}{|c|c|c|c|c|c|}
\hline $\begin{array}{l}\text { Dias de } \\
\text { secagem }\end{array}$ & $\begin{array}{c}\text { Massa } \\
(20 \text { endocarpos })(\mathrm{g})\end{array}$ & Germinação (\%) & Início da germinação (dias) & $\begin{array}{l}\text { Final da germinação } \\
\text { (dias) }\end{array}$ & $\begin{array}{l}\text { Tempo Médio da } \\
\text { germinação (dias) }\end{array}$ \\
\hline 1 & 106,3 & 0 & 0 & 0 & 0 \\
\hline 5 & 99,3 & 0 & 0 & 0 & 0 \\
\hline 10 & 74,3 & 5 & 176 & 176 & 176 \\
\hline 15 & 57,7 & 10 & 110 & 147 & 129 \\
\hline 20 & 50,3 & 5 & 137 & 137 & 137 \\
\hline 25 & 53,9 & 0 & 0 & 0 & 0 \\
\hline 30 & 40,4 & 40 & 59 & 144 & 105 \\
\hline 35 & 44,9 & 30 & 90 & 132 & 107 \\
\hline 40 & 40,3 & 40 & 11 & 126 & 81 \\
\hline 45 & 38,6 & 45 & 32 & 81 & 59 \\
\hline 50 & 39,1 & 35 & 37 & 123 & 84 \\
\hline 55 & 38,2 & 40 & 11 & 69 & 47 \\
\hline 60 & 40,5 & 30 & 57 & 95 & 66 \\
\hline 65 & 39,4 & 35 & 22 & 108 & 69 \\
\hline 70 & 38,8 & 10 & 68 & 96 & 82 \\
\hline 75 & 37,8 & 15 & 53 & 78 & 53 \\
\hline 80 & 37,4 & 30 & 8 & 58 & 38 \\
\hline 85 & 36,6 & 45 & 23 & 43 & 38 \\
\hline 90 & 36,5 & 25 & 20 & 25 & 23 \\
\hline 95 & 38,9 & 50 & 17 & 44 & 28 \\
\hline 100 & 40,3 & 20 & 15 & 25 & 21 \\
\hline 105 & 37,3 & 40 & 14 & 70 & 29 \\
\hline 110 & 37,1 & 10 & 25 & 65 & 45 \\
\hline 115 & 42,7 & 40 & 20 & 60 & 32 \\
\hline 120 & 44,7 & 40 & 15 & 35 & 26 \\
\hline 125 & 40,3 & 55 & 19 & 35 & 26 \\
\hline 130 & 40,2 & 45 & 19 & 34 & 26 \\
\hline 135 & 38,9 & 70 & 18 & 32 & 22 \\
\hline
\end{tabular}


secagem, refletiriam, apenas, a capacidade germinativa das sementes que já haviam superado a dormência. Este fato, de certo modo, contraria a informação feita por Carvalho et al. (2000) de que as sementes desta espécie são de baixo poder germinativo.

O espesso endocarpo lenhoso do taperebá, que impõe resistência mecânica ao crescimento do embrião durante a germinação, provavelmente não é o único fator que retarda a germinação das sementes. Carvalho et al. (1998), estudando as características físicas de germinação de algumas frutíferas da Amazônia, observaram a ocorrência de mais de uma semente em endocarpos de taperebá e variações, em termos de dias requeridos para a germinação, entre as sementes, dentro do mesmo endocarpo.

Neste experimento, foi observado que a semente de taperebá necessitaria de um período de armazenamento para o embrião superar a dormência, como indicado pelo início, pelo final e pelo tempo médio de germinação das sementes (Tabela 1). Carvalho et al. (1998) encontraram valores de germinação do taperebá de 76,3\%, com início da germinação aos 160 dias, final aos 844 dias e tempo médio aos 457 dias.

Observou-se redução do tempo médio requerido para a germinação com a elevação do tempo de dessecamento das sementes (endocarpos), fato que pode ser atribuído à imaturidade do embrião. Vale ressaltar que a diminuição no tempo médio de germinação ocorreu independentemente do percentual de germinação dos tratamentos, provavelmente devido ao alto índice de sementes inviáveis ou de endocarpos sem sementes, característicos dessa espécie que não foram avaliadas neste trabalho (Carvalho et al., 1998).

Os endocarpos de Spondias mombin são euricárpicos apresentando formas elíptica, obovóide, ovóide e globosa. Apresentam uma extremidade afunilada e a outra arredondada ou, às vezes, truncada, com margem inteira (Figura 2).

Em corte transversal, os endocarpos apresentam-se envolvidos por fibras esponjosas e as sementes por uma estrutura radial (estrelar) de consistência lenhosa; observam-se cinco lóculos dispostos radialmente com duas ou três sementes viáveis para a maioria dos endocarpos examinados (Figura 3), características semelhantes às descritas por Lozano (1986). Apresentam as seguintes dimensões: comprimento 29,82 - 31,15 mm com média de 30,52 mm; diâmetro de

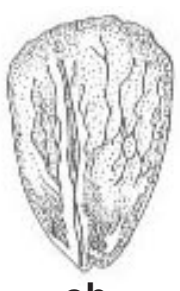

ob

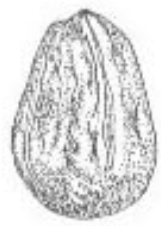

ov

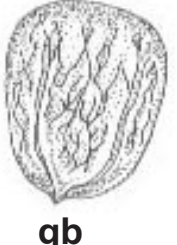

gb

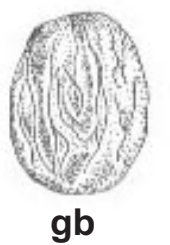

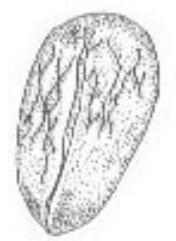

el

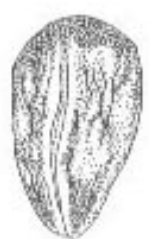

ob

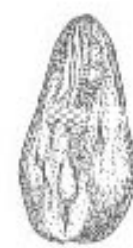

ov

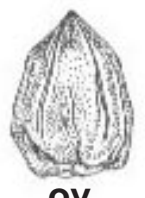

OV
FIGURA 2 - Diversas formas (euricápicos) das unidades de dispersão (endocarpos) de Spondias mombin L. el - elíptico; gb globoso; ob - obovóide; ov - ovóide

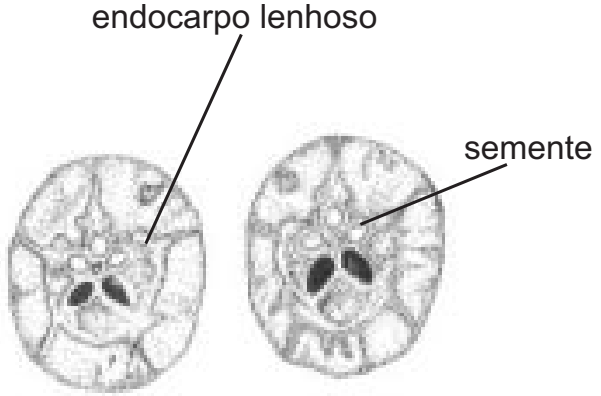

FIGURA 3 - Corte transversal do endocarpo de Spondias mombin L, mostrando a posição das sementes no endocarpo.

19,90 - 21,20 mm e média de 20,58 mm (Tabela 2). Souza et al. (2000) encontraram valores para a biometria dos endocarpos da mesma espécie de 25,2 a 34,8 mm de comprimento e 13,2 a 16,4 mm de diâmetro.

As sementes são alongadas, elípticas e de comprimentos diferentes no mesmo endocarpo, com tegumento delgado; embrião reto, com eixo hipocótilo-radícula curto e cotilédones levemente planoconvexos, acompanhando o formato da semente. Observou-se que o tamanho pode estar relacionado com o vigor da semente, pois a semente maior foi a primeira a emitir a raiz primária durante a germinação.

Cada endocarpo apresentou de 5 a 6 lóculos e 1 a 4 sementes (Tabela 2). Esses resultados são próximos aos obtidos por Souza et al. (2000) e Pereira (1996), citado por Souza et al. (2000). Porém, Carvalho et al. (1998) e Cardoso (1992), citado por Souza et al. (2000), encontraram, com maior freqüência, uma semente por endocarpo.

A germinação do taperebá é do tipo epígeo fanerocotiledonar. Por se tratar de um endocarpo contendo mais de uma semente, a protrusão da raiz primária se confunde com as fibras que envolvem o endocarpo, podendo, ainda, emergir mais de uma radícula na parte truncada ou achatada do endocarpo. Inicialmente, a radícula apresentase cilíndrica, glabra e hialina; com o alongamento, fica de coloração esbranquiçada e há o aparecimento da região pilífera com pêlos simples, curtos e esparsos, observados somente sob lupa. Neste estádio, observa-se a protrusão do hipocótilo em forma de joelho dobrado na mesma extremidade onde ocorre a protrusão da raiz. As raízes secundárias aparecem simultaneamente com o desprendimento dos cotilédones (Figura 4).

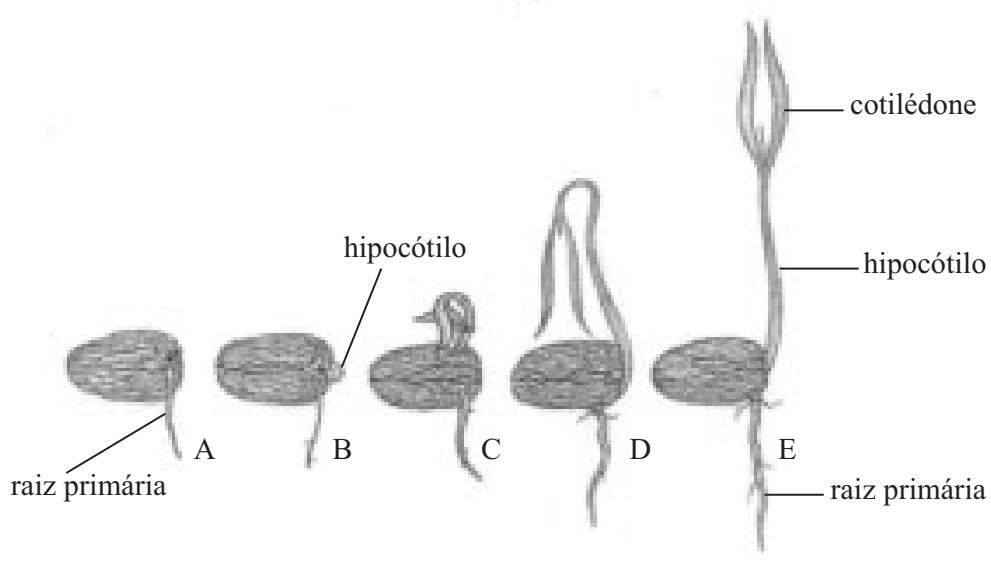

FIGURA 4 - Fases da germinação de Spondias mombin L. A - emissão da raiz primária; B - emissão do hipocótilo; C desprendimento dos cotilédones; D - fase de gancho; $\mathrm{E}$ germinação completa.

TABELA 2 - Biometria da unidade de dispersão (endocarpo) de taperebá (Spondias mombin L.).

\begin{tabular}{|c|c|c|c|c|}
\hline & Comprimento (mm) & Diâmetro (mm) & № de lóculos & $\mathrm{N}^{\mathrm{o}}$ de sementes \\
\hline Média & 30,52 & 20,58 & 5,3 & 2,5 \\
\hline Desvio-padrão & 0,73 & 0,64 & 0,46 & 0,72 \\
\hline Máximo & 31,15 & 21,20 & 6,0 & 4,0 \\
\hline Mínimo & 29,82 & 19,90 & 5,0 & 1,0 \\
\hline
\end{tabular}


Com o alongamento da raiz, evidencia-se o aparecimento do hipocótilo inicialmente curvo, de coloração amarelada. Com a liberação total dos cotilédones, o hipocótilo é epígeo, cilíndrico, longo, reto, subherbáceo, glabro de coloração esbranquiçada e ápice amarelado. Os cotilédones apresentam-se inicialmente amarelos, sésseis, com lâminas paralelas, delgados, porém não foliáceos, planos, lanceolados com nervuras não evidentes e glabros nas duas faces (Figura 4).

O sistema radicular apresenta-se pivotante, sub-herbáceo quando a plântula ainda apresenta os cotilédones e sublenhoso após a queda dos cotilédones, com poucas raízes secundárias. O hipocótilo permanece longo, cilíndrico, reto, de coloração castanha, glabro até próximo ao epicótilo, no qual apresenta alguns pêlos semelhantes aos do epicótilo. Epicótilo cilíndrico, curto, verde-claro, herbáceo, delgado, coberto por pêlos ralos, simples, curvos (ciliar) e curtos (Figura 5).

O primeiro par de protófilo apresenta-se composto, imparipinado, trifoliolado, oposto; pecíolo longo, reto, cilíndrico-convexo, com pêlos simples curtos e curvos. Folíolos subsésseis, verde-claros, com ambas as faces glabras e nervura principal pilosa com pêlos semelhantes aos do pecíolo; apresentam-se de forma lanceolada com base decurrente, ápice agudo e margens serreadas. O segundo protófilo se desenvolve alternadamente, apresentando-se composto, imparipinado, trifoliolado, com características semelhantes ao primeiro. O metáfilo apresenta-se composto com dois pares de folíolos opostos e um simples; pecíolo e ráquis longo, cilíndrico-convexo, com pêlos semelhantes ao epicótilo, somente na parte convexa. Gema axilar comprimida cônica e glabra (Figura 5).

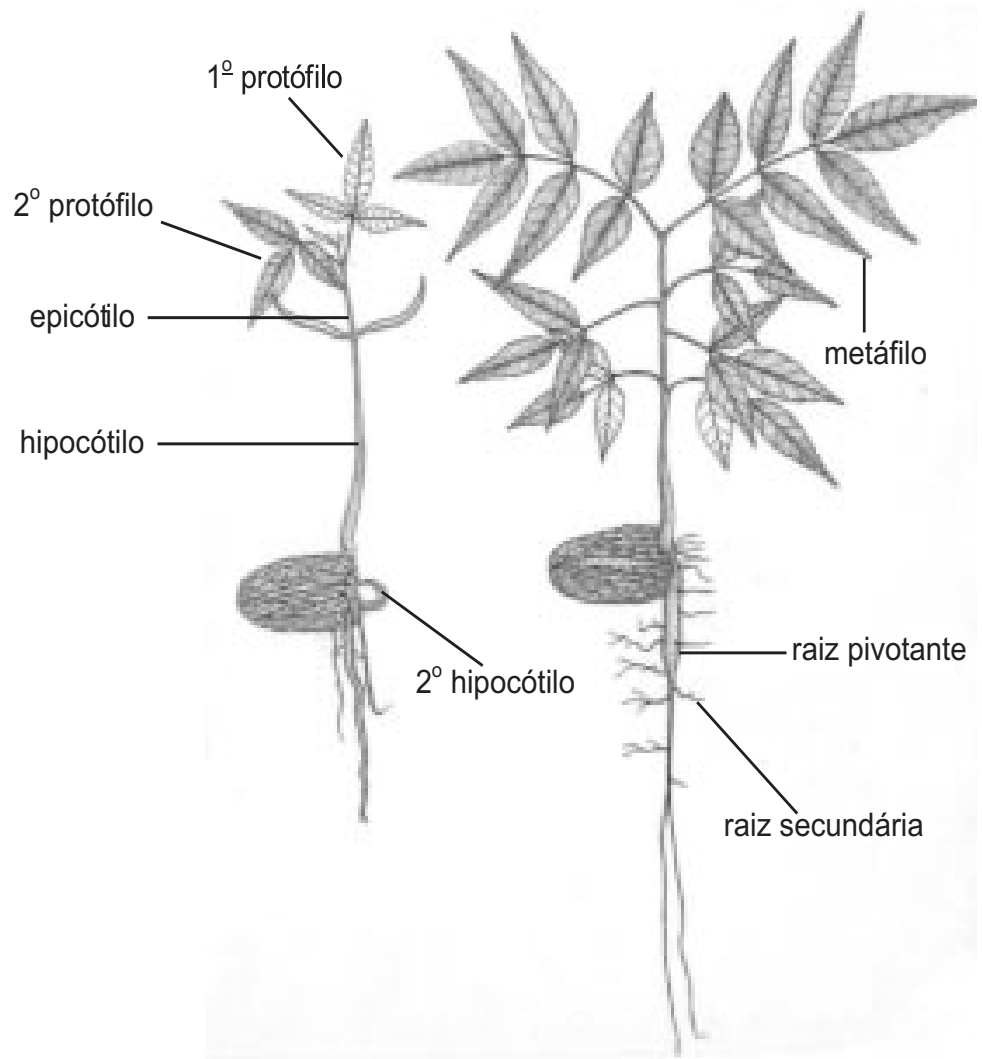

FIGURA 5 - Características da plântula normal de Spondias mombin L.
De cada endocarpo, pode germinar mais de uma semente ao mesmo tempo, ocorrência muito comum nos endocarpos das matrizes estudadas. Porém, observou-se que apenas uma raiz era vigorosa e, muitas vezes, as outras raízes somente apareciam quando a plântula estava completamente formada; além disso, as plântulas eram muito semelhantes, sem anomalia aparente. Uma vez que as plântulas emergidas são semelhantes, recomenda-se efetuar o desbaste na fase de gancho ou no momento do transplante para evitar a eliminação daquelas que apresentam a raiz vigorosa.

\section{REFERÊNCIAS}

AMORIM, I. L. Morfologia de frutos, sementes, germinação, plântulas e mudas de espécies florestais da Região de Lavras. 1996. 127f. (Dissertação de Mestrado) - Universidade Federal de Lavras, Lavras, 1996.

ARAÚJO, S. S.; MATOS, V. P. Morfologia de sementes e plântulas de Cassia fistula L. Revista Árvore, Viçosa, v.15, n.13, p.217223, 1991.

BRAGA, R. Cajazeira, In: BRAGA, R. Plantas do Nordeste, especialmente do Ceará. 3.ed. Mossoró: ESAM, 1976. 103p (Coleção Mossorense, 42).

CARVALHO, J. E. U. de; NASCIMENTO, W. M. O. DO; MÜLLER, C. H. Características físicas e de germinação de sementes de espécies frutíferas nativas da Amazônia. Belém: Embrapa-CPATU, 1998. 18p. (Boletim de Pesquisa, 203).

CAVALCANTE, P. B. Frutas comestíveis da Amazônia. 4.ed. Belém: Museu Emílio Goeld, 1976. 646 p.

DUKE. Keys for the identification of seedlings of some prominent woody species in eight forest types in Puerto Rico. Missouri Botanic Garden, St. Louis, v.52, n.3, p.314-350, 1965.

FONT-QUER, P. Dicionário de Botânica. Barcelona: Labor, 1963. $1244 \mathrm{p}$

JOHANSEN, D. A.. Plant microtechnique. New York: McGraw-Hill Book, 1940. 523p.

LOZANO, N. B. Desarrolo y anatomia del fruto del joba (Spondias mombin L.). Caldasia, Bogotá, v. 14, n. 68/70, p.465-490, 1986.

MELO, M. G. G. 2001. Análise morfológica de sementes, germinação e plântulas de cinco espécies arbóreas em sistemas agroflorestais na Amazônia. 2001.112f. Dissertação (Mestrado em Ciências Agrárias) - Universidade Federal do Amazonas, Manaus, 2001

SILVA, J. B.; NAKAGAWA, J. Estudos de fórmulas para cálculo de velocidade de germinação. Informativo ABRATES, Londrina, v.5, n.1, p.62-73, 1995.

SOUZA, F. X. de; SOUZA, F. H. L.; FREITAS, J. B. S.; ROSSETTI, A. G. Aspectos morfológicos da unidade de dispersão de cajazeira. Pesquisa Agropecuária Brasileira, Brasília, v.35, n.1, p.215220,2000 . 